\title{
Capacidad jurídica y acceso a la justicia de las personas con discapacidad en Argentina
}

\author{
Juridical capacity and access to justice for persons with disabilities in \\ Argentina
}

\begin{abstract}
Resumen
El presente artículo analiza el ciclo de las políticas públicas -conformación de la agenda, discusión de alternativas, toma de decisiones, implementación y evaluación- sobre discapacidad en Argentina relacionado con el derecho al acceso a la justicia y a la capacidad jurídica desde la perspectiva de la Convención sobre los Derechos de las Personas con Discapacidad. Metodológicamente se propone un circuito de análisis que va de la sociedad al Estado -a través de la política- y del Estado a la sociedad -a través de las políticas. Se toma como casos el Protocolo para el acceso a la justicia de las personas con discapacidad. Propuestas para un trato adecuado, aprobado por RES N ${ }^{\circ} 1417 / 13$ de la Defensoría General de la Nación y el Código Civil y Comercial de la Nación, aprobado por Ley 26.994 (B.O. del 01/08/2015).
\end{abstract}

\section{Palabras clave}

Acceso a la justicia, discapacidad, capacidad jurídica, políticas públicas, personas con discapacidad.

\begin{abstract}
This article analyzes the cycle of public policies -conformation of the agenda, discussion of alternatives, decision-making, implementation and evaluation- on disability in Argentina related to the right to access to justice and legal capacity from the perspective of the Convention on the Rights of Persons with Disabilities. Methodologically a circuit of analysis is proposed that goes from society to the State -through politics- and from the State to society -through policies. The protocol for access to justice for persons with disabilities. Proposals for an adequate treatment, approved by RES N ${ }^{\circ} 1417 / 13$ of the National Ombudsman's Office and the Civil and Commercial Code of the Nation, approved by Law 26.994 (B.O. of 01/08/2015) are taken as cases.
\end{abstract}

\section{Keywords}

Access to justice, disability, juridical capacity, public policies, people with disabilities.

\section{Juan Manuel Iglesias Frecha <jmiglesiasfrecha@gmail.com>}

Universidad Nacional de La Plata. Argentina

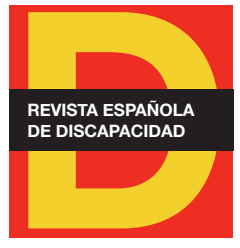

Para citar:

Iglesias, J. M. (2019): "Capacidad jurídica y acceso a la justicia de las personas con discapacidad en Argentina". Revista Española de Discapacidad, 7 (II): 79-101.

Doi: <https://doi.org/10.5569/23405104.07.02.05>

Fecha de recepción: 14-12-2018 Fecha de aceptación: 29-09-2019 


\section{Introducción}

El estudio de las políticas públicas cobra gran relevancia puesto que en Argentina, y en varios países de la región latinoamericana, se discute el rol del Estado en relación al mercado y su posición preponderante en la toma de decisiones para garantizar el desarrollo económico y la inclusión social de las personas con discapacidad (PCD), a través de la eliminación de barreras que permitan el pleno goce de los derechos reconocidos en los instrumentos internacionales de derechos humanos. En este sentido, en la República Argentina se encuentran vigentes en la actualidad dos convenciones sobre discapacidad: la Convención Interamericana para la Eliminación de Todas las Formas de Discriminación contra las Personas con Discapacidad (CIADDIS) de la Organización de los Estados Americanos (OEA), suscrita en 1999 y aprobada por Ley 25.280; y la Convención sobre los Derechos de las Personas con Discapacidad (CDPD) y su Protocolo Facultativo de Naciones Unidas (ONU), aprobada por Ley 26.378 e incorporada al bloque federal de constitucionalidad por la Ley 27.044 en 2014. Es en el marco de esta última, y en virtud del art. 75, inc. 22 de la Constitución Nacional que establece la adecuación de la normativa interna a los tratados internacionales de derechos humanos, donde el acceso a la justicia y la presunción de la capacidad jurídica aparecen consideradas, por primera vez, como derechos humanos en concordancia con los principios del modelo social de la discapacidad (Palacios, 2008).

En este sentido, el objetivo de este artículo consiste en analizar, desde una perspectiva relacional e histórica, el ciclo de las políticas públicas relacionadas con el derecho al acceso a la justicia y a la capacidad jurídica de las personas con discapacidad a partir de dos estudios de caso: el Protocolo para el acceso a la justicia de las personas con discapacidad. Propuestas para un trato adecuado, aprobado por Resolución N 1417/13 de la Defensoría General de la Nación, y el Código Civil y Comercial de la Nación (CCCN) aprobado por Ley 26.994 de 2014, en vigor desde agosto de 2015. En términos generales, se busca analizar la economía política (actores, intereses, ideologías y lógicas de comportamiento) que articula la hechura e impacto de la intervención política sobre los derechos de las personas con discapacidad, con especial énfasis en el derecho al acceso a la justicia y a la capacidad jurídica. En otras palabras, se busca dar cuenta de la dinámica político-social que forja estas propiedades en términos de prioridades y cursos de acción convenientes, a partir de una propuesta teórico-metodológica diferente de la que predomina en la literatura especializada, que aborda estos temas desde perspectivas estrictamente legalistas que se centran casi exclusivamente en la etapa de implementación, desconociendo o minimizando el papel que desempeñan los recursos materiales y simbólicos movilizados por los distintos actores que entran en el juego de las políticas públicas¹.

Para ello, en el siguiente apartado se despliegan los alcances conceptuales de la terminología empleada, al mismo tiempo que sus vinculaciones. A continuación, se desarrolla la propuesta metodológica que pretende ser superadora de los enfoques tradicionales de políticas públicas, para luego adentrarse en el análisis de las políticas mencionadas en el primer párrafo. Por último, se efectúan una serie de reflexiones finales tendentes a integrar, desde una teoría de las relaciones de poder de carácter general, los desarrollos alcanzados.

1. Entre estos últimos podemos mencionar, a título ilustrativo, la propuesta de Bernardini, L. et al. (2018), quienes al indagar acerca de los retos en el acceso a la justicia de las personas con discapacidad en el ámbito penal, en el marco de un estudio comparado entre la Ciudad de México y la Ciudad de Buenos Aires, procuran conocer si la discapacidad es identificada en las primeras etapas del proceso penal y, posteriormente, si esta identificación conlleva a la implementación de apoyos y ajustes en los procedimientos, para advertirnos acerca de la necesidad de generación e implementación de programas que brinden una propuesta de intervención concreta para superar las barreras que enfrentan las personas con discapacidad Intelectual y psicosocial para la efectiva aplicación de la CDPD. 
2. Marco teórico: entre el derecho al acceso a la justicia y el derecho a la capacidad jurídica

La pregunta que se intenta responder en este apartado puede resumirse de la siguiente manera: ¿en qué consiste el derecho al acceso a la justicia y en qué se relaciona con la capacidad jurídica de ejercicio?

El acceso a la justicia puede ser definido, en términos generales, como el derecho humano fundamental que se relaciona con la posibilidad que tienen las personas de reclamar y hacer valer sus derechos, en igualdad de condiciones, eliminando cualquier situación de desigualdad, discriminación, violencia, maltrato o abuso. El Comité sobre los Derechos de las Personas con Discapacidad, durante el $11^{\circ}$ período de sesiones, ha señalado que "el reconocimiento del derecho a la capacidad jurídica es esencial para el acceso a la justicia" y que para que las personas con discapacidad puedan exigir el cumplimiento de sus derechos y obligaciones en igualdad de condiciones con las demás "debe reconocérseles la personalidad jurídica con la misma capacidad ante las cortes de justicia y los tribunales" (Naciones Unidas, 2014: 34).

La CDPD reconoce el derecho al acceso a la justicia, en su art. 13, como la posibilidad que tienen las personas con discapacidad de tener "acceso a la justicia en igualdad de condiciones con las demás, incluso mediante ajustes de procedimiento y adecuados a la edad, para facilitar el desempeño de las funciones efectivas de esas personas como participantes directos e indirectos, incluida la declaración como testigos, en todos los procedimientos judiciales, con inclusión de la etapa de investigación y otras etapas preliminares". La participación directa hace alusión a los casos en que las personas con discapacidad actúan como demandante o demandado, es decir, como partes oficiales en el procedimiento; la participación indirecta, en cambio, se refiere a otras funciones que intervienen en la administración de justicia, como la de testigo, jurado, juez o abogado.

El derecho a la capacidad jurídica, por su parte, se encuentra reconocido en el art. 12 de la Convención de la siguiente manera: "...las personas con discapacidad tienen capacidad jurídica en igualdad de condiciones con las demás en todos los aspectos de la vida". En suma, el reconocimiento de la capacidad jurídica aparece vinculado de manera indisoluble con el disfrute de muchos otros derechos humanos establecidos en la Convención sobre los derechos de las personas con discapacidad, entre ellos el derecho al acceso a la justicia.

Sin embargo, es harto sabido que las personas con discapacidad se encuentran con muchos obstáculos que dificultan el goce efectivo de sus derechos cuando participan de los procesos judiciales y/o administrativos. Esto obedece a múltiples razones: dificultades en el acceso a la información sobre sus derechos y la forma de ejercerlos; trato no adecuado por parte de las fuerzas de seguridad en los diferentes procedimientos, al igual que la modalidad en que los operadores judiciales interactúan con las PCD; abordajes incorrectos en los procedimientos periciales; $y$ el desconocimiento por parte de los actores judiciales de la normativa vigente sobre discapacidad, entre otras.

En este sentido, el Comité ha señalado que los Estados partes deben velar por que las personas con discapacidad "tengan acceso a representación jurídica en igualdad de condiciones con las demás (...), garantizando que las personas que vean obstaculizado su derecho a la capacidad jurídica tengan la oportunidad de impugnar esos obstáculos —en su propio nombre o por medio de su representante legal—y de defender 
sus derechos ante los tribunales" (Naciones Unidas, 2014: 34), y que tanto jueces como agentes de policía, trabajadores sociales y otras personas que intervienen en las respuestas iniciales deben recibir, por un lado, la información necesaria para que sepan que las personas con discapacidad tienen personalidad jurídica plena y den el mismo crédito a sus denuncias y declaraciones que el que darían a las de personas sin discapacidad y, por otro lado, la capacitación para sensibilizarlos sobre su obligación de respetar la capacidad jurídica de las personas con discapacidad, con inclusión de su capacidad legal y de su legitimación para actuar (Naciones Unidas, 2014: 35).

En relación con la aplicación del artículo 13 de la Convención, el informe anual de la Oficina del Alto Comisionado de las Naciones Unidas para los Derechos Humanos, elaborado durante su $37^{\circ}$ período de sesiones, entre los días 26 de febrero y 26 de marzo de 2018, establece las normas que rigen el acceso equitativo y efectivo de las personas con discapacidad a la justicia, determinando buenas prácticas y formulando recomendaciones. En este sentido, afirma que el derecho de acceso a la justicia de las personas con discapacidad implica "no solo la eliminación de barreras a fin de asegurar el acceso a los procedimientos judiciales para interponer recursos adecuados en igualdad de condiciones con las demás personas, sino también la promoción de la intervención y participación activas de las personas con discapacidad en la administración de justicia" (Naciones Unidas, 2018: 5). Asimismo, señala que el art. 13 tiene por objeto "promover el derecho de las personas con discapacidad a contribuir y participar en todos los aspectos de la administración de justicia y otros procesos jurídicos, como parte de una ciudadanía activa para conformar la sociedad en que vivimos" (Naciones Unidas, 2018: 16). Por último, resalta el hecho de que el acceso a la justicia es un derecho transversal, que debería interpretarse en consonancia con todos los principios y obligaciones de la CDPD, particularmente con el art. 5 sobre la igualdad y la no discriminación, a fin de asegurar que las personas con discapacidad tengan acceso a la justicia en igualdad de condiciones con las demás, y que, para ser efectivo, "requiere derechos habilitadores para las personas con discapacidad, en especial el igual reconocimiento como persona ante la ley (art. 12), y la accesibilidad, que comprende medios diversos de comunicación y de acceso a la información (arts. 9 y 21)" (Naciones Unidas, 2018: 16).

De esto último se desprende que el reconocimiento de estos derechos implica el cumplimiento de una serie de obligaciones por parte de los Estados partes de la Convención. En efecto, los art. 4.1.a y 4.1.b de la misma señalan que deben "adoptar todas las medidas legislativas (...) que sean pertinentes para hacer efectivos los derechos", y "tomar todas las medidas pertinentes, incluidas medidas legislativas para modificar o derogar leyes, reglamentos, costumbres y prácticas existentes que constituyan discriminación contra las personas con discapacidad". Además, a fin de promover la igualdad y eliminar la discriminación, el art. 5.3, establece que deben adoptar "todas las medidas pertinentes para asegurar la realización de ajustes razonables", medidas que se vinculan al principio de no discriminación y que se desprenden directamente de los derechos civiles y políticos, por lo que no pueden ser objeto de realización progresiva².

Cabe recalcar, en este sentido, que el Comité encargado de supervisar el Pacto Internacional de Derechos Civiles y Políticos, en la Observación General № 31 expresó que "[T]odos los poderes públicos (Ejecutivo, Legislativo y Judicial) y demás autoridades públicas o gubernamentales, sea cual fuere su rango —nacional, regional o local- están en condiciones de comprometer la responsabilidad del Estado parte. El Poder Eje-

2. En las negociaciones relativas al artículo 13 de la Convención se debatió si la terminología que debía adoptarse era "ajuste de procedimiento" o "ajuste razonable" y se decidió abandonar la referencia a "razonable". La decisión de descartar voluntariamente el término "razonable" puso de relieve el hecho de que, a diferencia de los ajustes razonables, los ajustes de procedimiento no están sujetos al criterio de proporcionalidad, por lo que su denegación constituye discriminación por motivos de discapacidad (Naciones Unidas, 2018). 
cutivo, que por lo común representa al Estado Parte en el plano internacional, señaladamente ante el Comité no puede aducir el hecho de que un acto incompatible con una disposición del Pacto ha sido realizado por otro poder público para tratar de liberar al Estado parte de responsabilidad por el acto y de la consiguiente incompatibilidad. Esta interpretación se desprende directamente del principio enunciado en el art. 27 de la Convención de Viena sobre el derecho de los tratados, en virtud del cual un Estado Parte 'no podrá invocar las disposiciones de su derecho interno como justificación del incumplimiento de un tratado'. Si bien el párrafo $2^{\circ}$ del art. $2^{\circ}$ permite que los Estados parte hagan efectivos los derechos reconocidos en el Pacto con arreglo a los procedimientos constitucionales internos, se desprende del mismo principio que los Estados parte no pueden invocar las disposiciones de su derecho constitucional ni otros elementos del derecho interno para justificar el incumplimiento o la inaplicación de las obligaciones contraídas en virtud del Tratado. A este respecto, el Comité recuerda a los Estados parte de estructura federal lo estipulado en el art. 50, en virtud del cual las disposiciones del Pacto 'serán aplicables a todas las partes componentes de los Estados federales, sin limitación ni excepción alguna”' (Naciones Unidas, 2004: 4).

En suma, el goce efectivo del derecho al acceso a la justicia y el reconocimiento de la capacidad jurídica de las personas con discapacidad implica tanto el cumplimiento de obligaciones "negativas" como "positivas" de los Estados parte de la Convención, en la medida en que son estos quienes deben tomar acciones que garanticen su goce efectivo, ya sea a través de la toma de medidas administrativas, legislativas e incluso jurisdiccionales para remover los obstáculos que obstruyen cualquiera de estos derechos, como de la abstención de realizar acciones discriminatorias, tales como no proporcionar ajustes de procedimiento cuando una persona con discapacidad concreta los requiera. Asimismo, el cumplimiento de estas obligaciones positivas y negativas, conforme al art. 33 de la Convención, implica el deber de los Estados de implementar una reforma procedimental en la sanción de las leyes que garantice el derecho de participación directa de las organizaciones de personas con discapacidad. Es así como se torna necesario elaborar un circuito de análisis, que permita indagar las relaciones de la sociedad al Estado -a través de la política- y del Estado a la sociedad -a través de las políticas.

\section{Metodología para el análisis de las políticas públicas}

Históricamente, los estudios sobre políticas públicas tendieron a separar la etapa del diseño y de la ejecución, de la política y la administración. Jaime et al. (2013: 102) señalan que la implementación "ha sido una de las etapas tal vez menos estudiadas puesto que desde sus comienzos y hasta inicios de los años 70 la investigación en el campo de las ciencias de políticas estuvo centrada en la decisión y las etapas que la preparan (anteceden). La corriente dominante en aquellos años sostenía que para lograr un buen resultado solo era necesario mejorar la calidad analítica e informativa de la decisión (esto es, los modelos causales implícitos en ellas)".

En contraposición, el proceso constitutivo de las políticas públicas puede ser concebido como un "conjunto de iniciativas y respuestas, manifiestas o implícitas, que observadas en un momento histórico y en un contexto determinado permiten inferir la posición del Estado frente a una cuestión que atañe a sectores significati- 
vos de la sociedad" (Oszlak y O’ Donnell, 1997: 113), en el marco de una compleja trama de intervenciones en la que se comprometen personas, recursos, organizaciones, capacidad de gestión y se ponen en juego intereses y relaciones de poder.

En el ámbito local, Acuña y Bulit Goñi (2010: 45) han desarrollado un esquema para el análisis de las políticas públicas de discapacidad a partir de la teoría de los sistemas, imputando "un mínimo de unidad y consistencia como para poder asumir condiciones básicas de integración, coordinación y gobernabilidad". Sin embargo, este uso, por así decir, epojético ${ }^{3}$ de la noción de "sistema", trae aparejado una serie de problemas de índole metodológica, como es el establecimiento de un criterio de demarcación que permita delimitar aquellas políticas o programas que dotan al mentado sistema de unicidad de aquellas que no: las políticas macroeconómicas que inciden, directa o indirectamente, sobre el destino de los derechos de las personas con discapacidad; la dinámica de determinadas prácticas estatales que no tienen por objeto inmediato la atención de las demandas de las personas con discapacidad, pero que, aun así, inciden de un modo u otro en el curso de su desarrollo, son tan solo algunos de los tantos ejemplos que advierten acerca de la dificultad con la que se enfrentan los investigadores que adoptan la perspectiva sistémica a la hora de delimitar su objeto de estudio.

Por el contrario, en este artículo se parte de la premisa que las políticas públicas están atravesadas por un conjunto de instituciones, actores y prácticas heterogéneas, que hacen que la noción de "ciclo" sea la más adecuada para su análisis (Aguilar Villanueva, 1993a; Tamayo Sáez, 1997). Este ciclo está compuesto por "etapas", que incluyen el establecimiento de metas y objetivos de las políticas, la definición de las prioridades y las estrategias de intervención, la asignación de responsabilidades y funciones a las áreas y los actores involucrados en la implementación de la política, la distribución de los recursos necesarios para el cumplimiento de las actividades ligadas a las responsabilidades y funciones asignadas, la sistematización de la información y evaluación de las políticas públicas, y eventual redefinición de las políticas en función de las conclusiones de la evaluación, entre otras.

Desde esta perspectiva, empero, no se trata de reconocer una direccionalidad unívoca en los ciclos de las políticas públicas, sino de elaborar un circuito de análisis que permita indagar las relaciones de la sociedad al Estado -a través de la política- y del Estado a la sociedad -a través de las políticas. Así, las políticas públicas emergen de la interacción entre Estado y Sociedad y atraviesa distintas etapas: conformación de la agenda, discusión de alternativas, toma de decisiones, implementación y evaluación. Este es un proceso social y político complejo que no transcurre en forma lineal, sino que emerge del entrecruzamiento de diferentes posiciones de los actores, que configura un campo en disputa ${ }^{4}$. Este circuito de ida y vuelta permite estudiar no solo el papel de las organizaciones políticas y estatales en la elaboración de políticas, sino también un aspecto menos atendido en la literatura, como es la trama asociativa de la sociedad civil (actores, redes y organizaciones del "tercer sector") en su doble papel de partícipes y/o destinatarios de las políticas públicas. Estas interacciones son "objetivas", en la medida en que su estudio pueda limitarse al registro de comportamientos, y, al mismo tiempo, "subjetivas" en la medida en que se refieren a cómo cada actor define y redefine

3. El término epojé, transliterado también a veces como epoché o epokhe proviene del griego énoxń y significa "suspensión". El uso que se le da a este concepto en el presente artículo, no obstante, es tomado de la fenomenología husserliana y que consiste en la puesta entre paréntesis (parentetización) de las doctrinas sobre la realidad, como es la imputación de un mínimo de unidad y consistencia para el análisis de las políticas públicas en tanto sistemas.

4. La noción de "campo" refiere a una "red de posiciones objetivas que se definen en su existencia por su situación actual o potencial en la distribución de las diferentes especies de capitales económicos, sociales y educativos" (Bourdieu, 1984: 135). Se trata de espacios sociales diferenciados que articulan un conjunto de relaciones o posiciones sociales que se definen las unas en relación a las otras de acuerdo a un tipo de poder o capital específico, tales como la capacidad de organización y de gestión de recursos, entre otros. 
la cuestión y percibe la toma de posición de otros actores: se trata de reglas de juego, formales e informales, a través de las cuales diversos actores e instituciones interactúan movilizando recursos (económicos, simbólicos y culturales). De estas dos dimensiones se derivan acciones más o menos organizadas alrededor de cuestiones socialmente problematizadas por parte de actores e instituciones (Oszlak y O'Donnell, 1997). En resumen: a) las políticas públicas emergen de la interacción entre Estado y sociedad y atraviesan distintas etapas: conformación de la agenda, discusión de alternativas, toma de decisiones, implementación y evaluación; b) estas etapas no se presentan de modo lineal, sino que el proceso constitutivo de las políticas públicas se da a partir de una compleja trama de intervenciones en la que se comprometen personas, recursos, organizaciones y capacidad de gestión donde se ponen en juego intereses y relaciones de poder; c) este conjunto de instituciones, actores y prácticas (público-estatales y privadas) conforman un espacio de relaciones, con una historicidad propia, que incide, de un modo u otro, en el goce efectivo de los derechos las personas con discapacidad; e) las instituciones, actores y prácticas que conforman este espacio varían con el paso del tiempo.

Es desde esta perspectiva que me propongo analizar la dinámica político-social que forja estas propiedades en términos de prioridades y cursos de acción específicos que tienen por fin garantizar el derecho al acceso a la justicia de las personas con discapacidad y a la capacidad jurídica; sin pretender abarcar la totalidad de instituciones, actores y prácticas que conforman este campo, sino tan solo aquellos reconocidos como socialmente válidos por los actores en condiciones de disputarse el sentido y alcance de las nociones de derecho al acceso a la justicia y a la capacidad jurídica.

\section{El Protocolo para el acceso a la justicia de las personas con discapacidad. Propuestas para un trato adecuado}

El ciclo de la política pública que culminó con la implementación del Protocolo de base para el acceso a la justicia de personas con discapacidad puede ser descrito como un proceso complejo de negociación y cooperación que involucró la participación de diversos actores, nacionales e internacionales.

La Red por los Derechos de las Personas con Discapacidad (REDI) y la organización Rehabilitación Internacional (RI) fueron las primeras organizaciones de la sociedad civil que buscaron poner en agenda la problemática del acceso a la justicia. Así, con el objetivo de establecer un plan de acción hacia la reforma legal prevista por el art. 4 de la Convención, elaboraron, en noviembre de 2010, un documento titulado Capacidad jurídica y acceso a la justicia: una propuesta de reforma legal desde las organizaciones de personas con discapacidad. En este documento efectuaron algunas recomendaciones generales, entre ellas: consultar a las personas con discapacidad y organizaciones de personas con discapacidad; establecer mecanismos para que estas participen en la formulación y aplicación de legislación que las afecte, en el marco de un proceso formal, amplio, transparente y democrático de participación; e impulsar la conformación de un grupo de trabajo intergubernamental e intersectorial, con enfoque de derechos humanos (integrado por expertos independientes, sociedad civil, funcionarios gubernamentales, defensorías del pueblo, universidades, miembros de la judicatura) que cuente con apoyo logístico y financiero del Estado, para que se dedique a la revisión integral de la normativa y propuestas de adecuación a la CDPD, y que impulse los proyectos hacia el Poder Legislativo. 
La respuesta del Estado no se hizo esperar. Así, en 2011 se creó el Programa Nacional de Asistencia para las Personas con Discapacidad en sus relaciones con la Justicia, en la órbita de la Secretaría de Justicia del Ministerio de Justicia y Derechos Humanos; en 2012 se creó, por Res. DGN 499/12, el Programa de Salud, Discapacidad y Adultos Mayores, bajo la órbita de la Secretaría General de Política Institucional de la Defensoría General de la Nación, con el objetivo de brindar la colaboración que requieran magistrados y funcionarios para la remoción de barreras estructurales de las personas que se encuentran en situación de vulnerabilidad -entre ellas las personas con discapacidad-, a fin de facilitarles el acceso a la justicia5; y, desde fines de 2012 y durante todo el año 2013, el Ministerio Público de la Defensa, a través de dicho programa, participó como coordinador en un proyecto orientado a la reducción de obstáculos al acceso a la justicia de las personas con discapacidad, en el marco del Programa EUROsociAL II y el Programa para la Cohesión Social en América Latina. Asimismo, el Ministerio tuvo como socios operativos a las entidades Justice Coopération Internationale $(\mathrm{JCl})$ y Fundación del Consejo General de la Abogacía Española (Fundación Abogacía Española), bajo la coordinación de France Expertise Internationale (FEI), que financió gran parte de las actividades llevadas a cabo.

En el marco de este último, las actividades fueron iniciadas con una mesa de diálogo que reunió al equipo local de las instituciones organizadoras, el Ministerio de Justicia y Derechos Humanos de la Nación a través del Programa Nacional de Asistencia para las Personas con Discapacidad en sus Relaciones con la Administración de Justicia (ADAJUS), la Subsecretaría de Promoción de Derechos Humanos, dependiente de la Secretaría de Derechos Humanos, y el Ministerio Público Fiscal de la Ciudad Autónoma de Buenos Aires a través de la Oficina de Acceso a Justicia, dependiente de la Secretaría General de Acceso a Justicia y Derechos Humanos. Por otro lado, el Ministerio Público de la Defensa, a través del Programa sobre Temáticas de Salud, Discapacidad y Adultos Mayores, quien depende, a su vez, de la Secretaría General de Política Institucional de la Defensoría General de la Nación, actuó en calidad de coordinador. Asimismo, se contó con la presencia de personas con discapacidad y familiares, y organizaciones de derechos humanos involucradas en la promoción de los derechos de las personas con discapacidad, con el objeto de identificar, mediante el intercambio de experiencias, las barreras socioculturales que se presentan a las personas con discapacidad en el acceso a la justicia.

En cuanto a la etapa diagnóstica de esta política pública que comenzaba a perfilarse, fueron determinantes los resultados arrojados por encuesta realizada en el ámbito del Poder Judicial de la Provincia de Buenos Aires con el apoyo de la Suprema Corte de Justicia de la Provincia de Buenos Aires, donde muchos de los operadores entrevistados manifestaron que con la integración de personas con discapacidad "los procesos judiciales serán más largos y complicados"; que "no comprenden los procedimientos y términos jurídicos" y que "no pueden aportar pruebas"; que habría que "exigir que solo actúen mediante representación" y "obviar la presencia de la persona con discapacidad prefiriendo dirigirse a un tercero", entre otras manifestaciones discriminatorias (Jorge, 2013: 199). En este sentido, se propuso la elaboración de un protocolo (guía de buenas prácticas), con la asistencia técnica de expertos, que recogiera recomendaciones y propuestas sobre

5. No está de más mencionar que la Corte Interamericana de Derechos Humanos en el caso 12539 "S.C.F. y familiares Vs. Argentina", del 31 de agosto de 2012, recordó que "en el marco de las obligaciones derivadas de los artículos 1.1 y 2 de la Convención, y según los estándares desarrollados en la presente Sentencia (supra párrs. 125 a 139), los Estados deben adoptar medidas para reducir las limitaciones o barreras y para dar el trato preferente apropiado a las personas con discapacidad, a fin de conseguir los objetivos de la plena participación e igualdad dentro de la sociedad para todas ellas" (párr. 300). 
el trato adecuado que debe brindarse a las personas con discapacidad, orientado hacia los operadores del servicio de justicia, siguiendo los postulados establecidos por la Convención y las Reglas de Brasilia ${ }^{6}$.

La etapa de diseño se hizo sobre la base de un trabajo de recopilación documental, de información y de análisis que implicó, por un lado, un análisis cualitativo referido esencialmente a la información obtenida en forma directa con las personas seleccionadas para la aplicación de cuestionarios -a operadores del servicio de justicia-, entrevistas personales -a magistrados y personas con discapacidad-y grupos de discusión -con personas con discapacidad y organizaciones vinculadas con la temática-; y, por el otro, un examen cuantitativo fundamentado en la información estadística existente con respecto al acceso a la justicia de las personas con discapacidad. Abordado desde una perspectiva interdisciplinaria y teniendo en cuenta los aportes de los distintos actores involucrados. Una vez recabada dicha información, se dispuso la participación de la Dra. María Soledad Cisternas Reyes, Presidenta del Comité de Naciones Unidas para las Personas con Discapacidad, y de la Dra. María Silvia Villaverde, Juez de los Tribunales de Familia del Departamento Judicial de Lomas de Zamora, como expertas internacional y nacional, respectivamente, con el objeto de acompañar y brindar apoyo técnico específico a las instituciones participantes en la elaboración del protocolo. Luego, la Dra. Cisternas diseñó un plan de trabajo a seguir para la elaboración del protocolo que consistió en analizar la normativa vigente en materia de discapacidad, las distintas instancias de intervención en el marco de los procedimientos judiciales y la interacción de los operadores con las personas con discapacidad, las barreras percibidas por las personas con discapacidad en el ámbito de justicia, el nivel de toma de conciencia por parte de los actores del sistema de justicia sobre la base de los postulados que surgen de la CDPD, entre otras cuestiones relacionadas con la temática.

El documento final se dio a llamar Protocolo de base de actuación para el acceso a justicia de las personas con discapacidad, aunque no sería el definitivo. Inicialmente, el protocolo se estructuró en cuatro capítulos: el primero de ellos denominado Organización judicial y principios generales del derecho en la República Argentina, describe el panorama institucional y axiológico del sistema de justicia del país; el segundo capítulo, Fundamentos teóricos del protocolo, invita a examinar el modelo social y de derechos humanos de las personas con discapacidad, a la luz del nuevo paradigma reconocido en la CDPD; el capítulo tercero introduce experiencias concretas de buenas prácticas en el acceso a la justicia de las personas con discapacidad en la doctrina comparada (de España y Costa Rica); y, el cuarto capítulo, Orientaciones específicas para el acceso a la justicia de las personas con discapacidad: detección de barreras socio culturales/actitudinales y recomendaciones, procura identificar las barreras específicas que experimentan las personas con discapacidad en el acceso a la justicia, por tipologías seleccionadas, así como efectuar recomendaciones concretas hacia el sistema judicial y sus operadores.

Sin embargo, en la elaboración final de dicho documento, con el fin de facilitar la difusión e implementación del protocolo, se elaboró una versión ágil más reducida, que prescindió del capítulo sobre la organización judicial y los principios generales del derecho en la República Argentina; se sintetizó el capítulo sobre los fundamentos teóricos; y se reorganizó y adecuó el capítulo referido a las orientaciones específicas para el acceso a la justicia de las personas con discapacidad, la detección de barreras socio culturales/actitudinales y las recomendaciones, conforme las Reglas de Brasilia y la CDPD. Finalmente, mediante Resolución DGN

6. Cabe destacar que las Reglas de Brasilia reconocen la existencia de poblaciones más vulnerables que otras en el ejercicio efectivo de todos los derechos consagrados en los instrumentos internacionales de derechos humanos como aquellas que "por razón de su edad, género, estado físico o mental, o por circunstancias sociales, económicas, étnicas y/o culturales, encuentran especiales dificultades para ejercitar con plenitud ante el sistema de justicia los derechos reconocidos por el ordenamiento jurídico" (art. 3). 
$N^{\circ} 1417 / 13$, se aprobó el documento definitivo que fue titulado Protocolo para el acceso a la justicia de las personas con discapacidad. Propuestas para un trato adecuado.

La etapa de implementación constó de dos grandes etapas. En primer lugar, se trabajó la órbita de la Secretaría General de Política Institucional de la Defensoría General en la "toma de conciencia" por parte de los operadores y operadoras del sistema sobre las barreras que obstaculizan la participación, directa e indirecta, de aquellas en los procedimientos judiciales, incluyendo la etapa de investigación y otras etapas preliminares. En este sentido, se brindaron recomendaciones y orientaciones prácticas acerca del trato que debe procurarse a las personas con discapacidad a jueces, fiscales, defensores, otros operadores de justicia y personal auxiliar de la administración de justicia. En segundo lugar, se buscó la instrucción a los magistrados, funcionarios y empleados de la institución judicial para que, en sus respectivos ámbitos de actuación funcional, apliquen las propuestas y recomendaciones allí contenidas, y se impulsen medidas orientadas a su difusión y adopción. Para ello, se elaboró un taller denominado Taller de formación y toma de conciencia, con el objetivo de brindar herramientas a los operadores del sistema de justicia para que puedan hacer efectivos los derechos humanos reconocidos a las personas con discapacidad y de posibilitar la aplicación diaria de las buenas prácticas emanadas del protocolo referido. En tercer lugar, se implementó un Plan de formación de formadores, a fin de que pueda ser puesto a disposición de distintos replicadores representantes del Poder Judicial, Ministerio Público Fiscal y Ministerio Público de la Defensa, tanto a nivel federal como local. Este plan de acción, al igual que el anterior, trabajó en la sensibilización y provisión de herramientas a los operadores que trabajan diariamente con las personas con discapacidad de todo el país, con el doble objetivo de adecuar la atención que prestan a las exigencias de los nuevos paradigmas que imponen los compromisos internacionales y de contribuir a superar la desconfianza entre las personas que intentan acceder al sistema de justicia y las instituciones que deben garantizar ese acceso. Constó de 70 replicadores del sistema de justicia integrantes de las instituciones organizadoras, y de las 24 escuelas judiciales provinciales del país, apoyadas por la Junta Federal de Cortes y Tribunales Superiores de Justicia de las provincias argentinas (JUFEJUS). En este caso, fue el Programa EUROsociAL el que financió la participación total de 16 representantes judiciales de las distintas provincias del país (seis de ellos defensores públicos oficiales federales designados por Resolución DGN No 1364/2013), a los efectos de que se constituyan como replicadores y se garantice la difusión e implementación del Protocolo en diferentes ámbitos del sistema de justicia argentino, y el alojamiento de los 24 representantes designados por JUFEJUS.

Si bien hasta aquí las etapas de diseño e implementación guardan coherencia lógica entre sí, la etapa de evaluación, en cambio, se caracteriza por la falta de información pública de parte del Estado y por la falta de recursos económicos y logísticos necesarios de parte de la sociedad civil. En el primero de los casos, el Estado se limita a identificar una serie de "buenas prácticas", tales como el accionar del Juzgado Nacional de Primera Instancia en el Civil N 7, en los autos T., M. H. s/ Artículo 152 Ter Código Civil, del 13 de mayo de 2014, que dictó la primera sentencia del país redactada en lenguaje sencillo, así como los dictámenes emitidos por la Dra. María Adelina Navarro Lahitte S., titular de la Curaduría Pública № 18 de la Defensoría General de la Nación, entre otras. En el caso de la sociedad civil, es posible identificar tres categorías de actores: 1) actores judiciales, como el caso la Dra. Villaverde, Juez de los Tribunales de Familia del Departamento Judicial de Lomas de Zamora y experta nacional en el diseño y la elaboración del Protocolo; 2) actores internacionales, como son los organismos internacionales de derechos humanos dependientes de las Naciones Unidas; y 3) actores de la sociedad civil, como son las organizaciones no gubernamentales y de personas con discapacidad, tales como la REDI, el Centro de Estudios Legales y Sociales (CELS), la Federación Argentina de Instituciones de Cie- 
gos y Ambliopes (FAICA), Federación Argentina de Entidades Pro Atención a las Personas con Discapacidad Intelectual (FENDIM) y Asociación por los Derechos Civiles (ADC), entre otras. Así, mientras que los actores académicos y los organismos internacionales coinciden en resaltar la falta de coordinación interinstitucional e interprofesional para la remoción de las barreras sistémicas a la efectividad de un modelo de protección integral de los derechos humanos, y de capacitación de los operadores en el modelo de los derechos humanos, en especial de jueces, personal sanitario y operadores del sistema de recopilación de datos y estadísticas en el modelo social de la discapacidad (Naciones Unidas, 2012), desde las organizaciones no gubernamentales y de personas con discapacidad, en cambio, se denuncia la persistente vulneración de su derecho al acceso a la justicia, sobre la base de una investigación hecha por el CELS $(2015)^{7}$ incluida dentro del Informe alternativo Situación de la discapacidad en Argentina- 2013/2017, sobre la persistencia de barreras para el goce efectivo del derecho al acceso a la justicia, entre ellas: la tutela efectiva del acceso a la justicia, que se ve alterada por la restricción a la capacidad jurídica, la imposibilidad de participar en el proceso y, finalmente, por la falta de seguimiento en la ejecución de las sentencias y la ausencia de revisión periódica para revertir las disposiciones más restrictivas de derechos; el derecho a defensa en el marco de procesos judiciales, que se ve socavado por las restricciones a la capacidad de ejercicio que limitan la capacidad para elegir, designar o remover libremente a un letrado; el derecho a la asistencia letrada, que se ve fraguado por el poco contacto personal con la persona representada y las internaciones cronificadas y ordenadas judicialmente desde tiempos anteriores a la sanción de la Ley Nacional de Salud Mental $26.657^{8}$ que suelen ser poco o nada monitoreadas; el derecho a ser oído, que se ve turbado debido a la persistencia de barreras institucionales, comunicacionales y actitudinales. En este sentido, señalan que de las personas que reportaron estar al tanto de la existencia de un proceso judicial de restricción a su capacidad jurídica, sólo un $4,4 \%$ manifestó conocer al juez a cargo y un $20 \%$ reportó no conocer a su curador designado.

Otro caso que es digno de ser mencionado en relación con la etapa de evaluación de esta política pública, son aquellas evaluaciones realizadas de manera conjunta entre distintos actores de la sociedad civil, como es el caso del Diagnóstico de necesidades jurídicas insatisfechas y niveles de acceso a la justicia, que fue realizado por la Facultad de Derecho de la Universidad de Buenos Aires, a solicitud del Ministerio de Justicia y Derechos Humanos de la Nación - Secretaría de Justicias, Subsecretaria de Acceso a la Justicia (2016). En este documento consta que el que el $26 \%$ del colectivo de las personas con discapacidad entrevistadas manifestó haber tenido al menos una necesidad jurídica insatisfecha en los últimos tres años, en el que el motivo "discriminación" representa el 22,0\% de los casos, seguido por "discriminación por condición de discapacidad" (13\%), "violencia institucional" (10,0\%), "discrecionalidad o arbitrariedad de la Administración" $(4 \%)$ y "exigencias burocráticas desmedidas e irrazonables" ( $3 \%) .{ }^{9}$ Aun así, este estudio no permite dar cuenta de la problemática del acceso a la justicia de las personas con discapacidad desde la perspectiva del art. 13 de la Convención, ya que la metodología y las técnicas de muestreo y de recolección de datos utilizadas revelan opiniones de las personas con discapacidad en relación a sus necesidades jurídicas insatisfechas, sin contar con categorías de respuestas abiertas o cerradas que permitan determinar la implementación o no de ajustes de procedimiento efectivos, entre otras cuestiones.

\footnotetext{
7. La investigación consta de 266 entrevistas a personas usuarias externadas, o en proceso de externación, de hospitales psiquiátricos en 4 jurisdicciones del país.

8. En el siguiente apartado se vuelve sobre este punto.

9. El estudio se realizó en todo el país, sobre la base de una muestra de 2800 hogares representativos de la población general, complementada por muestras referidas a tres grupos vulnerables en particular: población en condiciones de pobreza estructural, personas con discapacidad y población indígena. En el marco de dicho estudio, por "necesidad jurídica" se entiende "un asunto experimentado por una persona, que involucra cuestiones legales, independientemente de que la persona lo considere un asunto "legal" y de que la persona haya tomado o no acciones para resolverlo" (Ministerio de Justicia y Derechos Humanos de la Nación, 2016: 2).
} 
Para concluir este apartado, cabe señalar que sólo una sistematización adecuada de las buenas prácticas permitiría determinar los ajustes más apropiados para la participación efectiva de las personas con discapacidad, en beneficio de procedimientos futuros, y optimizar los recursos en el ámbito de la memoria institucional de la organización, para contribuir así al objetivo de que los sistemas jurisdiccionales sean más inclusivos y accesibles (Naciones Unidas, 2018). En este sentido, la iniciativa por parte del Ministerio de Justicia y Derechos Humanos de la Nación de involucrar a actores académicos en la etapa de diagnóstico y evaluación es un camino que merece ser transitado, pero siempre en articulación con los demás actores de la sociedad civil.

\section{El nuevo Código Civil y Comercial de la Nación: entre el modelo tutelar y la autonomía}

En este apartado se busca dar cuenta de las transformaciones del régimen de capacidad/incapacidad jurídica en Argentina a la luz del nuevo Código Civil y Comercial de la Nación, en virtud de la importancia que revisten los principios de igualdad de medios procesales y de no discriminación en relación con el acceso a la justicia de las personas con discapacidad en igualdad de condiciones con las demás.

El Código Civil (CC) que estuvo en vigencia desde el $1^{\circ}$ de enero de 1871 hasta 2015 -a pesar de sus modificaciones-, reguló la capacidad de hecho de las personas sobre la base de los cánones positivistas decimonónicos, consagrando un régimen dicotómico que distinguía entre personas sanas e insanas. Así, mientras que las primeras eran capaces de celebrar, en principio, por sí mismas, todo tipo de actos jurídicos; las segundas, en cambio, se encontraban incapacitadas absolutamente para realizar por sí cualquier acto de la vida civil. Bajo esta tónica, el codificador declaró como dementes a "los individuos de uno y otro sexo que se hallen en estado habitual de manía, demencia o imbecilidad, aunque tengan intervalos lúcidos o la manía sea parcial" (art. $141 \mathrm{CC}$ ). Estos últimos, conforme al art. 54 inc. a, CC, tenían una incapacidad absoluta. En consonancia, el Código estableció un esquema de representación legal con exclusión de la voluntad del incapaz; de apariencia necesaria, porque entendía que no podía prescindirse de ella (art. 56 CC); c) dual y conjunta, en tanto era conferida al representante legal individual (art. $57 \mathrm{CC}$ ) y al promiscuo (art. $59 \mathrm{CC}$ ), d) universalizante, ya que se extendía a todos los actos en que apareciera comprometido el representado en su interés personal o patrimonial (art. $62 \mathrm{CC}$ ); y, e) controlada, en cuanto estaba potencialmente sujeta al control judicial de su ejercicio (Olmo, 2015).

De este modo, el representante sustituía la voluntad de su representado al excluirlo por completo de la toma de cualquier tipo de decisión, so pretexto de la protección de su persona y en resguardo de sus bienes. El sistema se completaba con la institución de la curatela, que junto a la tutela de los menores también estaba orientada al resguardo o protección de la persona y de los bienes de los incapaces de hecho.

Con el objetivo de establecer un plan de acción hacia la reforma legal prevista por el art. 4 de la Convención y focalizándose en los arts. 12 y 13, la REDI y la organización Rehabilitación Internacional (RI) confeccionaron un documento titulado Capacidad jurídica y acceso a la justicia: una propuesta de reforma legal desde las organizaciones de personas con discapacidad. Entre las recomendaciones efectuadas, consideran prioritario "revisar diversas áreas temáticas de la legislación argentina, en las que históricamente se ha negado la ca- 
pacidad jurídica de las personas con discapacidad y desde donde debe iniciarse el proceso de reforma legal que transforme el actual modelo de sustitución en la toma de decisiones, hacia un modelo de ejercicio pleno y personal de los derechos, sostenido sobre la base de un sistema de apoyos para la persona" (Rehabilitación Internacional y Red por los Derechos de las Personas con Discapacidad, 2010: 20). Específicamente, sus críticas se dirigían hacia aquellas regulaciones que prescribían el sistema tutelar y proteccionista de sustitución en la toma de decisiones para las personas con discapacidad, e instauraban la figura del curador, quien debiendo guiarse por el criterio del denominado "buen padre de familia", terminaba ejerciendo los derechos en nombre de la persona y reemplazándola en todos los actos de la vida civil, administrando sus bienes, prescindiendo de su voluntad y participación e invalidando y nulificando cualquier acto que la persona pretenda realizar por sí misma. Asimismo, cuestionaban aquellas regulaciones que prescribían que el juez debe desplazar y reemplazar a la persona con discapacidad, en su carácter de parte en un juicio cualquiera (civil o comercial), en función de una declaración previa de incapacidad legal (interdicción), con la aplicación consecuente del sistema de sustitución en la toma de decisiones, bajo la figura del curador o representante legal.

Para lograr reducir la brecha entre el art.12 de la CDPD y la legislación argentina, señalaban los siguientes criterios mínimos a ser respetados: la superación de la dicotomía entre capacidad de derecho y capacidad de hecho, a efectos de reconocer la capacidad jurídica plena de toda persona con discapacidad y su consideración como sujeto de derechos, en igualdad de condiciones con las demás; y la eliminación de los procesos judiciales de insania e inhabilitación y el sistema legal de curatela y su reemplazo por un sistema de apoyos voluntarios para la toma de decisiones, basados en la confianza y siguiendo las preferencias de las personas con discapacidad que los requieran, a fin de ejercer su capacidad jurídica (Rehabilitación Internacional y Red por los Derechos de las Personas con Discapacidad, 2010). Por otro lado, en el marco del documento Informe alternativo - Situación de la Discapacidad en Argentina- 2008/2012, la REDI, el Centro de Estudios Legales y Sociales (CELS), la Federación Argentina de Instituciones de Ciegos y Ambliopes (FAICA), Federación Argentina de Entidades Pro Atención a las Personas con Discapacidad Intelectual (FENDIM) y la Asociación por los Derechos Civiles (ADC) denunciaban que "la ideología subyacente a este modelo parte del supuesto de que la persona sometida a un proceso judicial por cuestiones de salud mental en realidad es considerada un objeto de protección que necesita que el Estado la resguarde de los 'peligros de la vida en sociedad". (Red por los Derechos de las Personas con Discapacidad et al., 2012: 20).

En el ínterin, el régimen de capacidad sufrió una primera modificación sustancial en 2010 con la introducción del art. 152 ter en el Código Civil por Ley 26.657 de Salud Mental (LSM). Esta ley puso el foco en la exigencia de una intervención interdisciplinaria previa, en la personalización de la sentencia indicando los actos y funciones que se limitan y en la revisión periódica de la sentencia ${ }^{10}$. Respecto de la LSM, las organizaciones de la sociedad civil expresaron que, si bien dichos avances eran positivos, existían fuertes resistencias por parte de los/as operadores/as judiciales en torno a la puesta en práctica del artículo 152 ter, CC (Red por los Derechos de las Personas con Discapacidad et al., 2012). Asimismo, entendían que para que esta incorporación normativa se tradujera en una efectiva implementación, era necesario que existieran políticas integrales de capacitación de los operadores judiciales en todas las jurisdicciones, como así también que se adopten medidas estructurales para que el sistema de justicia revise todas las sentencias de restricciones a la capacidad jurídica declaradas con anterioridad a esta incorporación normativa y las ajuste a los nuevos estándares.

10. La primera modificación en el régimen de capacidad jurídica, no obstante, fue a través de la Ley 17.711 de 1968 de reforma del Código Civil. Dicha reforma incorporó el instituto de la inhabilitación para aquellas personas cuya afectación de salud mental no resultara tan gravosa: los "disminuidos en sus facultades mentales". A pesar de mantener la condición de capacidad de la persona, la inhabilitación importaba la designación de un "curador-asistente" que acompañaba al "inhabilitado" en la celebración de determinados actos. 
Es aquí cuando el Comité sobre los Derechos de las Personas con Discapacidad hizo específicas recomendaciones para la Argentina, con especial énfasis en las disposiciones del artículo 12 de la Convención, uno de los ejes de debate del Código Civil y Comercial. En las observaciones finales del Comité se incluyeron recomendaciones en relación con la cuestión de la capacidad y al cumplimiento de las disposiciones del art. 12 de la Convención, entre ellas, instar a la Argentina a que: "el Proyecto de Reforma y Unificación del Código Civil y Comercial elimine la figura de la interdicción judicial y que garantice en dicho proceso de revisión la participación efectiva de las organizaciones de personas con discapacidad"; "tome medidas para adoptar leyes y políticas por las que se reemplace el régimen de sustitución en la adopción de decisiones por el apoyo en la toma de decisiones que respete la autonomía, la voluntad y las preferencias de la persona"; "la puesta en marcha de talleres de capacitación sobre el modelo de derechos humanos de la discapacidad dirigida a jueces con la finalidad de que estos adopten el sistema de apoyo en la toma de decisiones en lugar de la tutela y la curatela" (Naciones Unidas, 2012: 20).

Como respuesta a la primera de estas cuestiones, el Estado informó al Comité la creación de la Comisión para la Elaboración del Proyecto de Ley de Reforma, Actualización y Unificación de los Códigos Civil y Comercial de la Nación, mediante Decreto $N^{\circ}$ 191/11, que fue remitido al Congreso de la Nación en junio de 2012. Asimismo, el Estado manifestó la existencia de una etapa de recolección de aportes de las distintas áreas del Poder Ejecutivo Nacional y de la Sociedad Civil, previo a su envío al Congreso Nacional para su tratamiento, destacando el aporte brindado desde el Grupo de Trabajo de Armonización Legislativa del Observatorio de la Discapacidad.

Las organizaciones negaron la existencia de dichas instancias de participación, aduciendo que si bien una de las organizaciones firmantes del informe alternativo había participado en una reunión del Grupo de Trabajo de Armonización Legislativa del mencionado Observatorio de la Discapacidad (la REDI), no habían existido de hecho instancias de participación formales que contemplasen un lapso de tiempo razonable para el tratamiento de los temas, abiertas a toda la sociedad civil y con alcance federal. Además, con relación al texto final del proyecto enviado al Congreso Nacional manifestaron que, lejos de adoptar integralmente la recomendación propuesta por el Grupo de Trabajo de Armonización Legislativa del Observatorio de la Discapacidad, solamente se habían incorporado algunas modificaciones en forma parcial y desintegrada, resultando un texto final que conservaba severas incompatibilidades con el mandato de la Convención.

En paralelo, distintas organizaciones de la sociedad civil elaboraron un documento titulado No a la muerte civil de nadie (Red por los Derechos de las Personas con Discapacidad et al., 2012), en el que denunciaban los puntos sobres los cuales el anteproyecto era contrario la Convención. Concretamente, rechazaban la posibilidad de declarar a una persona como incapaz absoluta (contraviniendo el art. 12, CDPD); el hecho de que la persona no fuese considerada un fin en sí mismo ni en igualdad a otras personas, y que su voluntad y autonomía no fueran siquiera tenidas en cuenta; la persistencia de una concepción médico-biológica de la discapacidad contraria al modelo social que instaura la CDPD; que los sistemas de apoyos y salvaguardas fuesen malinterpretados por la reforma y pudieran volverse en contra de la voluntad de las personas en forma de medidas tutelares de restricción de derechos (escenario que contraviene el art. 12.3 y 12.4 de la CDPD); el sostenimiento de la controvertida figura del "curador" con las mismas funciones; que se aumentara la discrecionalidad del juez sobre la determinación de la capacidad jurídica de las personas, en un total desprecio por el debido proceso y el derecho de defensa (en contraposición al art. 13 de la CDPD); y, finalmente, y no por ello de menor importancia, que se estableciera una regulación discriminatoria por razones de discapacidad, contraviniendo los arts. 4 y 5, CDPD. 
En efecto, el artículo 32 del anteproyecto mantenía la facultad judicial de restringir la capacidad de "personas mayores de TRECE (13) años que padece una adicción o alteración mental permanente o prolongada, de suficiente gravedad, siempre que estime que del ejercicio de su plena capacidad puede resultar un daño a su persona o a sus bienes"; y conservaba la facultad judicial de declarar la incapacidad "Cuando por causa de enfermedad mental una persona mayor de TRECE (13) años de edad se encuentra en situación de falta absoluta de aptitud para dirigir su persona o administrar sus bienes" (Red por los Derechos de las Personas con Discapacidad et al., 2012: 21). En ambos casos, quedaba librada a la discrecionalidad judicial decidir si designar un/a curador/a como representante que sustituye la voluntad de la persona o determinar los apoyos que resulten necesarios, por lo que las organizaciones entendían que la implementación de estos últimos debía ser directriz obligatoria de las decisiones jurisdiccionales, al privilegiar la voluntad de la persona. Las organizaciones de personas con discapacidad entendían que era necesario abrir el debate parlamentario.

El Código Civil y Comercial de la Nación fue finalmente sancionado por Ley 26.994 el primero de octubre de 2014. El 19 de noviembre de 2014 el Estado argentino incorporó por Ley 27.044 a la Convención y su Protocolo Facultativo de Naciones Unidas a su bloque federal de constitucionalidad, por lo que no sólo quedaba obligado a adecuar su normativa interna en virtud del art. 4 CDPD, sino también en función de lo dispuesto por el art. 31 de la Constitución Nacional que establece la adecuación de la normativa interna a los tratados internacionales de Derechos Humanos. A la postre, unos meses antes, entre el 31 de marzo y el 11 de abril de 2014, el Comité de la Convención, atento a la discusión sobre el proceso de unificación y reforma del Código había emitido su primera Observación General, haciendo énfasis en la necesidad de abolir los sistemas de sustitución de voluntad y su reemplazo por uno que promoviera la autonomía y la toma de decisiones de la persona. Recuperando lo vertido por las organizaciones de personas con discapacidad, reafirmó que el hecho de que una persona tenga una discapacidad "no debe ser nunca motivo para negarle la capacidad jurídica ni ninguno de los derechos establecidos en el artículo 12" (Naciones Unidas, 2014: 9).

Sin embargo, a pesar de los denodados esfuerzos de las organizaciones de personas con discapacidad y las observaciones del Comité, el Código Civil y Comercial de la Nación terminó incluyendo un sistema de apoyos en relación a las restricciones a la capacidad, aunque sin eliminar el tradicional régimen de sustitución de voluntad de la curatela, que subsiste hasta la actualidad ${ }^{11}$. El art. 32 conservó la redacción del anteproyecto en cuanto a las restricciones a la capacidad ("El juez puede restringir la capacidad para determinados actos de una persona mayor de trece años que padece una adicción o una alteración mental permanente o prolongada, de suficiente gravedad, siempre que estime que del ejercicio de su plena capacidad puede resultar un daño a su persona o a sus bienes"), aunque modificó ligeramente el párrafo que regula la interdicción, que quedó redactado de la siguiente manera: "Por excepción, cuando la persona se encuentre absolutamente imposibilitada de interaccionar con su entorno y expresar su voluntad por cualquier modo, medio o formato adecuado y el sistema de apoyos resulte ineficaz, el juez puede declarar la incapacidad y designar un curador" (art. 32 in fine, CCCN).

En cuanto a las reglas que regulan el proceso de restricción al ejercicio de la capacidad jurídica, el inc. a) del art. 31, CCCN, consagra el principio de la capacidad general de ejercicio de la persona humana, disponiendo que las limitaciones a la capacidad son de carácter excepcional y se imponen siempre en beneficio de la persona. El inc. e) del mismo artículo establece que la persona tiene derecho a participar en el proceso

11. Para más información ver: Código Civil y Comercial de la Nación; Título I: Persona Humana; Capítulo 2: Capacidad (artículos 31-50). Para la regulación del régimen de la curatela: Capítulo 10 (arts. 100 a 140). 
judicial con asistencia letrada, que debe ser proporcionada por el Estado si carece de medios. El art. 35 establece el deber del juez de garantizar la inmediatez (ya no se trata una facultad), así como de implementar "ajustes razonables del procedimiento", una voz relativamente extraña que al no descartar el término "razonable", puede entrañar discriminación por motivos de discapacidad en relación con el derecho de acceso a la justicia, conforme al Informe del Alto Comisionado de Naciones Unidas (Naciones Unidas, 2018). El art. 36 , CCCN, le otorga un concreto carácter de parte a la persona con discapacidad que la exime respecto a la necesidad de precisar cada uno de los actos que la persona puede ejecutar, y la equipara con cualquier otra que reviste dicha calidad.

En cuanto a los "determinados actos" que el juez está facultado para restringir, el art. 32, CCCN, establece que "debe designar el o los apoyos necesarios que prevé el artículo 43, especificando las funciones con los ajustes razonables en función de las necesidades y circunstancias de la persona". El artículo 43, en este sentido, establece que se entiende por apoyo "cualquier medida de carácter judicial o extrajudicial que facilite a la persona que lo necesite la toma de decisiones para dirigir su persona, administrar sus bienes y celebrar actos jurídicos en general"; y que su función consiste en "promover la autonomía y facilitar la comunicación, la comprensión y la manifestación de voluntad de la persona para el ejercicio de sus derechos". Respecto de los apoyos "judiciales", señala que serán delimitados por la sentencia, tanto en sus funciones, como en las personas que los cumplen. El art. 101, inc. C., CCCN, contempla la posibilidad de que el juez pueda designar apoyos con funciones de representación para los actos indicados en la sentencia, que deben actuar según la voluntad y preferencias de la persona interesada, quien tiene el derecho al resto de salvaguardias que fija la Convención y el Código.

Ante el nuevo escenario inaugurado tras la sanción del Código Civil y Comercial de la Nación, las organizaciones de la sociedad civil, a través del informe alternativo presentado ante el Comité sobre los Derechos de las Personas Con Discapacidad en el $18^{\circ}$ período de sesiones para la evaluación de la situación de las personas con discapacidad en Argentina durante 2013-2017, manifiestan que representó "un avance relativo hacia el respeto del pleno ejercicio de la capacidad jurídica de las personas con discapacidad intelectual y psicosocial (...)" (Red por los Derechos de las Personas con Discapacidad et al., 2017: 10). Si bien destacaron la incorporación de la figura de los sistemas de apoyo, la delimitación de los alcances de la sentencia de interdicción y la obligatoriedad de su revisión periódica, cuestionaron lo contenido en el artículo 32 in fine del CCCN, mediante el cual el Estado mantuvo la posibilidad de restringir el ejercicio de la capacidad jurídica de forma limitada y específica en el marco de determinados supuestos, y en casos extremos, las figuras de la incapacitación y la curatela; denunciaron que "en la práctica se observan diferencias en la redacción de las nuevas sentencias de "determinación de apoyos para el ejercicio de la capacidad jurídica", que luego en su parte resolutiva regresan al modelo tutelar, designando curadores para unas funciones y apoyos para otras, o directamente asignando ambas funciones -representación y apoyo- en la misma figura del curador" (Red por los Derechos de las Personas con Discapacidad et al., 2017: 10). A la postre, señalan que resta avanzar en la revisión periódica de las sentencias de declaración de insania o inhabilitación dictadas según el régimen anterior, tal como ordena el artículo 40 del $C C C N$, afirmando que, en los hechos, aún conviven el modelo tutelar y el modelo centrado en la autonomía, prevaleciendo el potencial rol sustitutivo de terceros en la toma de decisiones (Red por los Derechos de las Personas con Discapacidad et al., 2017: 10-11).

Para evaluar los impactos del CCCN sobre el derecho a la capacidad jurídica y el acceso a la justicia no se disponen de datos oficiales sistematizados. Una vez más, resulta imperioso que el Estado suministre infor- 
mación no sólo acerca del alcance y del tipo de medidas de apoyo implementadas, sino también respecto de los ajustes razonables de procedimiento implementados.

Aun así, es posible aproximarse a través de fuentes de información secundarias. En este sentido, a partir de una sistematización de los fallos de la Cámara Nacional de Apelaciones en lo Civil de la Ciudad Autónoma de Buenos Aires (CABA) dictados entre el 01/08/2015 y el 31/07/2017 -es decir, dentro de los primeros dos años de vigencia del nuevo Código-, correspondientes al criterio de búsqueda "determinación de la capacidad" y "152 ter" publicados por el Centro de Información Judicial (https://www.cij.gov.ar/), es posible arribar a los siguientes resultados: el $56 \%$ de las sentencias publicadas (608) determinan o restringen la capacidad jurídica; el $35 \%$ corresponden a procesos anteriores que no brindan información alguna; el $8 \%$ corresponden a procesos de incapacitación; y el $1 \%$ a procesos de rehabilitación ${ }^{12}$.

Gráfico 1. Porcentaje de fallos correspondientes al criterio de búsqueda "determinación de la capacidad" y "152 ter" (2015-2017)

Confirmatorio (sin datos)

Capacidad restringida

Rehabilitación

Incapacidad

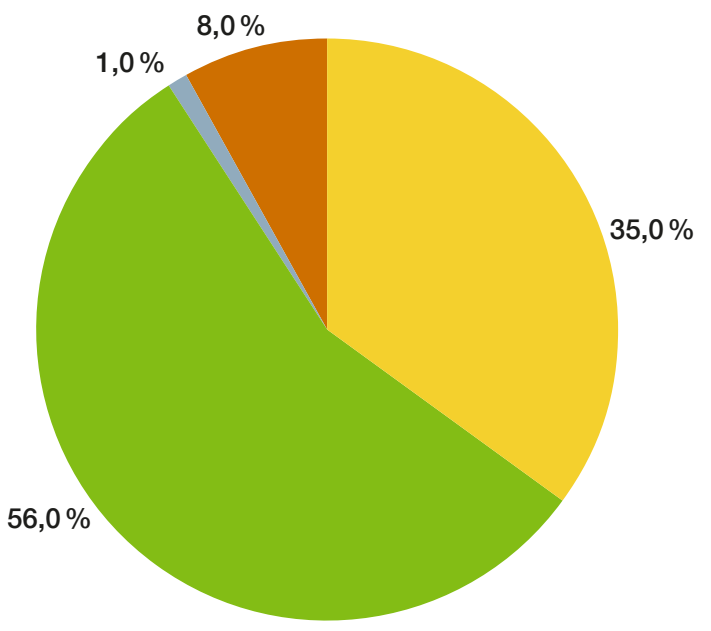

$\mathrm{N}=608$

Fuente: elaboración propia.

Si bien una primera lectura del Gráfico 1 podría sugerir que la tendencia es la presunción de la capacidad y que la incapacidad se configura como un supuesto excepcional, de conformidad con lo dispuesto por el Código y la CDPD, en la práctica judicial se observan diferencias en la redacción de las nuevas sentencias de "determinación de apoyos para el ejercicio de la capacidad jurídica", que luego en su parte resolutiva regresan al modelo tutelar, designando curadores para unas funciones y apoyos para otras, o directamente asignando ambas funciones - representación y apoyo- en la misma figura del curador.

12. La elaboración de la base de datos fue el resultado de un trabajo colectivo en el marco del proyecto DECYT 1617/2018, Facultad de Derecho, Universidad de Buenos Aires. Los detalles en cuanto a su metodología y técnicas de análisis de la información utilizadas se encuentran publicadas en Lafferriere (2018). 
Por otra parte, al tener en consideración el alcance de las medidas de apoyo implementadas en relación con los actos jurídicos restringidos que se indican en las sentencias, es posible observar que el $37 \%$ de las medidas de apoyo implementadas durante el período han sido dispuestas con funciones de representación de las personas con discapacidad en la celebración de sus actos, sustituyendo su voluntad en la toma de decisiones, mientras que el $63 \%$ restante con funciones de asistencia (ver Gráfico 2$)^{13}$.

\section{Gráfico 2. Porcentaje del tipo de medidas de apoyos determinadas en los tribunales civiles de la CABA (2015-2017)}

Apoyos con funciones de asistencia

Apovos con funciones de representación

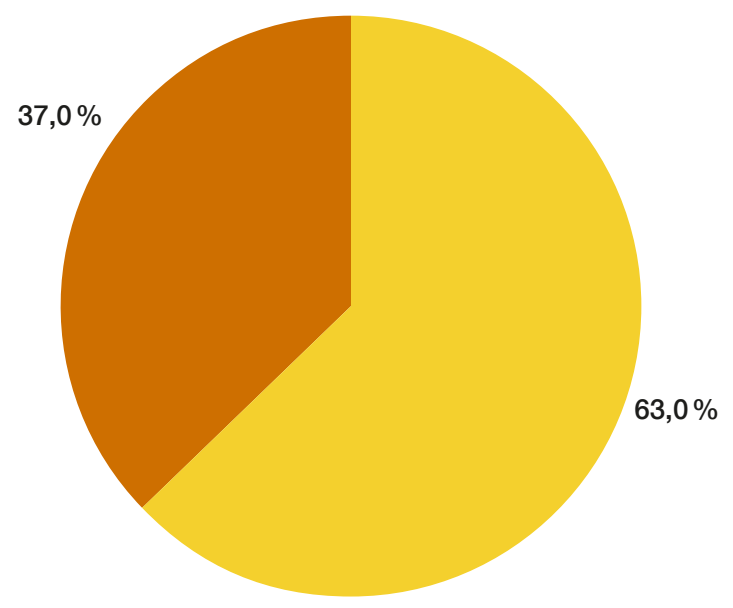

$\mathrm{N}=224$

Fuente: elaboración propia.

En suma, si bien el Comité fue claro en cuanto a la abolición de los regímenes de sustitución de la voluntad y la necesidad de su reemplazo por uno de apoyos en la toma de decisiones (Naciones Unidas, 2012), la redacción del actual $\mathrm{CCCN}$, así como las prácticas judiciales, contrarían en buena medida estas prerrogativas, corroborando la convivencia entre el modelo tutelar y el modelo centrado en la autonomía, así como la prevalencia del potencial rol sustitutivo de terceros en la toma de decisiones denunciadas por las organizaciones de PCD (Red por los Derechos de las Personas con Discapacidad et al., 2017). Por ejemplo, los fallos "W. L. V. s/ determinación de la capacidad" y "H. F. G. s/ determinación de la capacidad", en los que se procede a restringir la capacidad jurídica de la persona en los términos del art. 32, párrs. 20 y 3o, CCCN, atestiguan esta situación. En el primero de ellos se designa como "apoyo intenso" a la curadora oficial para que asista a la persona en la celebración de actos extrapatrimoniales (prestar el consentimiento informado para tratamientos médicos y psicoterapéuticos) y la represente en actos patrimoniales (actos de disposición y administración de sus bienes, así como de disposición de su pensión no contributiva); mientras que en el segundo se procede a la restricción de la capacidad "para todos los actos de la vida civil" y se nombra un apoyo. Incluso es posible identificar criterios que consagran esta situación anómala. Así, mientras que en el fallo "B., M. C. S/ determinación de la capacidad" del 18/05/2017, la sala I señala que "no hay que perder de vista que —aun en su faz representativa-, la función del apoyo no debe ser sustitutiva de la voluntad del causante sino siempre

13. Cabe mencionar que, en este caso, la falta de información es aún mayor, dado que, de las 341 sentencias de capacidad restringida de Cámara consultadas, sólo aportan información significativa sobre esta temática 224 , es decir, el $65 \%$. 
promoviendo la autonomía, facilitando la comunicación, comprensión y la manifestación de la voluntad de la causante"; en el fallo "C. M. M. s/ determinación de la capacidad" del 22/11/2016, la sala A sostiene que la función representativa de los apoyos "está reservada para situaciones particularmente graves, como resulta la presencia de patologías sobrevinientes o temporales que impiden totalmente al sujeto el ejercicio de la capacidad jurídica. También, para aquellos actos que deba realizar la persona con capacidad restringida por sí mismo que, dada la complejidad y la especificidad del asunto, requiera a criterio del juez ser sustituido por el apoyo en su celebración... Dichos actos serán llevados a cabo con autorización judicial”.

\section{Reflexiones finales}

En este apartado me propongo efectuar una "metaevaluación" sobre el ciclo de las políticas públicas estudiadas, entendiendo por tal una actividad programada de reflexión sobre la acción, basada en procedimientos sistemáticos de recolección, análisis e interpretación de información, con la finalidad de emitir juicios valorativos fundamentados y comunicables, sobre las actividades, resultados e impactos (Nirenberg et al., 2000). A lo largo de este artículo hemos podido ver desagregados en su accionar a distintos sectores de los aparatos estatales y de la sociedad civil alrededor de estas cuestiones socialmente problematizadas como son el derecho al acceso a la justicia y a la capacidad jurídica de las personas con discapacidad. En esta dinámica, Estado y sociedad configuran campos de relaciones sociales, relaciones de poder y de fuerza que se materializan en las capacidades diferenciales que detenta cada uno en la producción instrumental y simbólica de la discapacidad. Las sucesivas tomas de posición entre uno y otro son susceptibles de ser entendidas como luchas por la transformación de la realidad social en una u otra dirección. Lejos de ser informales, como suele enfatizar cierta literatura, las luchas por la imposición de sentido en el campo de la discapacidad tienden a asumir un carácter formal, altamente institucionalizado, por la propia configuración del campo que es estructurado por y estructurante de las prácticas de los distintos actores que participan en él: organismos internacionales, jueces, abogados, organizaciones de PCD, actores académicos, entre otros.

Por otro lado, al identificar y analizar las distintas etapas del ciclo de las políticas públicas en torno al derecho al acceso a la justicia y a la capacidad jurídica, hemos corroborado que no siguen una linealidad, sino que están atravesadas por avances y retrocesos, marchas y contramarchas. El proceso que culmina con la sanción y entrada en vigencia del actual Código puso en evidencia que las políticas públicas no son el resultado de respuestas aleatorias, carentes de sentido o direccionalidad, sino la expresión de las finalidades, mapas cognitivos e ideologías que los decisores -denominados en la literatura anglosajona policy makers- no pueden dejar de asumir. Así, la ideología médico-tutelar de jueces y legisladores, en determinados momentos históricos o en prácticas sociales concretas como son los procesos judiciales signados amplias facultades discrecionales de los jueces para valorar los dictámenes de los equipos interdisciplinarios, pueden terminar contrariando la aplicación efectiva de los principios del modelo social de la discapacidad pensados por los decisores, e incluso prolongando la existencia del modelo médico tutelar. Como señalan Oszlak y O'Donnell (1997: 5), "el rol del Estado en cada momento histórico podría concebirse como una expresión políticaideológica de esa agenda vigente". 
Esta última apreciación lleva a incorporar la dimensión de las relaciones de poder no sólo durante el proceso de implementación de una política, sino también de formación de la agenda, y a reconocer que los problemas son construcciones sociales que, como tales, comprometen a distintos actores en complejos entramados de intereses: la manera en cómo se define un asunto público (esto es, quién reconoce a la cuestión, bajo qué condiciones y con qué argumentos), condiciona los objetivos de la decisión pública y las opciones de acción (Elder y Cobb, 1993). Desde esta perspectiva, la "definición del problema" se plantea como una etapa interdependiente con la formación de agenda, en la medida en que existe una mutua influencia conceptual entre cómo se define un problema y el repertorio de soluciones. Aguilar Villanueva (1993b: 77-104) reconoce, en ese sentido, que muchas veces la definición del problema elaborada por el gobierno difiere de la definición de los afectados, por lo que se torna necesario introducir negociaciones, ajustes entre gobierno y sociedad: concebir los procesos de interdicción como la causa de la segregación de las personas con discapacidad puede entrar en contradicción con los intereses del Estado de asegurar cierto orden y cierta armonía social, por lo que el proceso de formación de la agenda revela no sólo vitalidad del gobierno en términos políticos, sino también la de los grupos y organizaciones que tienen fuerza para convertir las cuestiones socialmente problematizadas en asuntos públicos y prioridades de gobierno.

La utilización del lenguaje de derechos para imponer prioridades y cursos de acción estatal específicos, por tanto, revela las capacidades diferenciales de organización, recursos materiales y simbólicos de los distintos actores que conforman el campo de las políticas públicas sobre discapacidad. Quienes mayores probabilidades tienen de influir en las distintas etapas del ciclo de las políticas públicas son, precisamente, los que mayores capacidades acumulan. Una mirada histórica permite apreciar la importancia cada vez mayor de los instrumentos internacionales de derechos humanos en tanto herramientas indispensables para la creación de poderes y mecanismos de control ciudadanos tendentes a garantizar la plena la inclusión de las personas con discapacidad. Como señala Abramovich (2006: 41), "el lenguaje de derechos en las estrategias de desarrollo exige identificar algún tipo de mecanismo de seguimiento y responsabilidad que involucre a los actores del proceso de definición de políticas". 


\section{Referencias bibliográficas}

Abramovich, V. (2006): "Una aproximación al enfoque de derechos en las estrategias y políticas de desarrollo". Revista CEPAL, 88: 35-50.

Acuña, C. y Bulit Goñi, L. (2010): Políticas sobre la discapacidad en la Argentina: el desafío de hacer realidad los derechos. Buenos Aires: Siglo Veintiuno Editores.

Aguilar Villanueva, L. (1993a): La implementación de las políticas. México, D.F.: Porrúa.

Aguilar Villanueva, L. (1993b): Problemas públicos y agenda de gobierno. México, D.F.: Porrúa.

Argentina. Decreto № 191/11, de 23 de febrero de 2011, por el que se crea la Comisión para la Elaboración del Proyecto de Ley de Reforma, Actualización y Unificación de los Códigos Civil y Comercial de la Nación.

Argentina. Decreto Reglamentario No 603, de 28 de mayo de 2013, por el cual se reglamentó la Ley Nacional de Salud Mental, Boletín Oficial, 29 de mayo de 2013.

Argentina. Ley 24.430 , de 15 de diciembre de 1994, por la que se ordena la publicación del texto oficial de la Constitución Nacional (sancionada en 1853 con las reformas de los años 1860, 1866, 1898, 1957 y 1994).

Argentina. Ley 25.280, de 6 de julio de 2000, por la que se aprueba una Convención Interamericana para la eliminación de todas las formas de discriminación contra las personas con discapacidad, suscripta en Guatemala. Boletín Oficial, 4 de agosto de 2000, núm. 29455.

Argentina. Ley 26.378, de 21 de mayo de 2008, por la que se aprueba la Convención sobre los Derechos de las Personas con Discapacidad y su protocolo facultativo, aprobados mediante resolución de la Asamblea General de las Naciones Unidas del 13 de diciembre de 2006. Boletín Oficial, 9 de junio de 2008, núm. 31422.

Argentina. Ley 26.994, de 1 de octubre de 2014, por la que se aprobó el Código Civil y Comercial de la Nación. Boletín Oficial, 8 de octubre de 2014, núm. 32985.

Argentina. Ley 27.044, de 19 de noviembre de 2014, por la que se otorga jerarquía constitucional en los términos del artículo 75, inciso 22 de la Constitución Nacional, a la Convención sobre los Derechos de las Personas con Discapacidad. Boletín Oficial, 22 de diciembre de 2014, núm. 33035.

Argentina. Ley Nacional de Salud Mental 26.657, sancionada el 25 de noviembre 2010, Boletín Oficial, 3 de diciembre de 2010, núm. 32041.

Argentina. Resolución N 499/12, de 16 de mayo de 2012, de la Defensoría General de la Nación, por la que se crea el Programa sobre Temáticas de Salud, Discapacidad y Adultos Mayores.

Argentina. Resolución N 1364/13, de la Defensoría General de la Nación, mediante la cual se designaron seis defensores públicos oficiales federales a los efectos de que se constituyan como replicadores y se garantice la difusión e implementación del Protocolo en diferentes ámbitos del sistema de justicia argentino.

Argentina. Resolución № 1417/13, de 01 de noviembre de 2013, de la Defensoría General de la Nación, por la que se aprobó el Protocolo para el Acceso a la Justicia de las Personas con Discapacidad. Propuestas para un trato adecuado en su versión ágil de manera de facilitar su implementación.

Bernardini, L. et al. (2018): "Los retos en el acceso de las personas con discapacidad intelectual y psicosocial en el ámbito penal. Estudio comparativo de México y Buenos Aires". Revista Latinoamericana en Discapacidad, Sociedad y Derechos Humanos, 2 (2): 51-73. 
Bourdieu, P. (1984): Sociología y cultura. México: Grijalbo.

CELS (2015): Cruzar el muro: desafíos y propuestas para la externación del manicomio (en línea). <http://www.cels. org.ar/especiales/cruzarelmuro>, acceso 29 de agosto de 2019.

Elder, C. y Cobb, R. (1993): "Formación de la agenda", en Aguilar Villanueva, L. (ed.): Problemas públicos y agenda de gobierno. México: Miguel Ángel Porrúa.

Jaime, F. et al. (2013): Introducción al análisis de políticas públicas. Florencio Varela: Universidad Nacional Arturo Jauretche.

Jorge, E. (2013): "Informe del sondeo sobre el régimen legal para el ejercicio de la capacidad jurídica y acceso a la justicia de las personas con discapacidad (primera parte)", en Discapacidad, Justicia y Estado. Discriminación, estereotipos y toma de conciencia, 2. Buenos Aires: Infojus.

Lafferriere, J. (2018): "La recepción del modelo de apoyos para el ejercicio de la capacidad en los tribunales nacionales". La ley, 216: 1-8.

Ministerio de Justicia y Derechos Humanos de la Nación (2016): Diagnóstico de necesidades jurídicas insatisfechas y niveles de acceso a la justicia (en línea). <http://archivo2017.justicia2020.gob.ar/wp-content/ uploads/2017/05/DIAGN\%C3\%93STICO-DE-NECESIDADES-JUR\%C3\%8DDICAS-INSATISFECHAS.-Informe-Final-UBA.-5-Dic.-2016-1-1.pdf>, acceso 29 de agosto de 2019.

Naciones Unidas (2018): Informe anual del Alto Comisionado de las Naciones Unidas para los Derechos Humanos e informes de la Oficina del Alto Comisionado y del Secretario General A/HRC/37/25, 26 de febrero a 23 de marzo de 2018, sobre Derecho de acceso a la justicia en virtud del artículo 13 de la Convención sobre los Derechos de las Personas con Discapacidad, durante el $37^{\circ}$ período de sesiones, párrs. 12, 13, 15, 38, 54,55 y 56.

Naciones Unidas (2014): Observación general núm. 1 CRPD/C/GC/1 del Comité sobre los Derechos de las Personas con Discapacidad, 30 de marzo a 11 de abril de 2014, sobre el artículo 12: igual reconocimiento ante la ley, durante el $11^{\circ}$ período de sesiones, párrs. 9, 34, 35, 38 y 39.

Naciones Unidas (2012): Comité sobre los Derechos de las Personas con Discapacidad. Octavo período de sesiones CRPD/C/ARG/CO/1, Ginebra, 17 a 28 de septiembre de 2012, examen de los informes presentados por los Estados partes en virtud del artículo 35 de la Convención. Observaciones finales del Comité sobre los Derechos de las Personas con Discapacidad, párrs. 6, 8, 14, 22, 47, 48, 52 y 55.

Naciones Unidas (2004): Observación general núm. 31 [80] CCPR/C/21/Rev.1/Add.13 del Comité de Derechos Humanos, de 26 de mayo de 2004, durante el $80^{\circ}$ período de sesiones, sobre la naturaleza de la obligación jurídica general impuesta a los Estados parte. Aprobada el 29 de marzo de 2004 (2187 sesión), párr. 4.

Naciones Unidas (1969): Convención de Viena sobre el derecho de los tratados (en línea). < https://www.oas.org/ xxxivga/spanish/reference_docs/convencion_viena.pdf>, acceso 26 de noviembre de 2019.

Niremberg, O. et al. (2000): Evaluar para la transformación: innovaciones en la evaluación de programas y proyectos sociales. Buenos Aires: Paidós.

Olmo, J. (2015): Salud mental y discapacidad. Análisis del Código Civil y Comercial de la Nación -Ley 26994. Buenos Aires: Dunken.

Oszlak, O. y O’Donnell, G. (1997): “Estado y políticas estatales en América Latina: hacia una estrategia de investigación”. Redes, 2 (4): 99-128. 
Palacios, A. (2008): El modelo social de discapacidad: orígenes, caracterización y plasmación en la Convención Internacional sobre los Derechos de las Personas con Discapacidad. Madrid: CINCA.

Red por los Derechos de las Personas con Discapacidad et al. (2017): Informe alternativo. Situación de la discapacidad en Argentina-2013/2017" presentado ante el Comité sobre los derechos de las personas con discapacidad. 18 período de sesiones/evaluación sobre Argentina (en línea). <http://www.redi.org.ar/Documentos/Informes/Informe-alternativo-Argentina-2017/Informe-Alternativo-Argentina.pdf>, acceso 29 de agosto de 2019.

Red por los Derechos de las Personas con Discapacidad (2015): No a la muerte civil de nadie (en línea). <http:// www.redi.org.ar/Que-hacemos/Acceso-a-la-justicia/No-a-la-muerte-civil-de-nadie.pdf>, acceso 29 de agosto de 2019.

Red por los Derechos de las Personas con Discapacidad et al. (2012): Informe alternativo. Situación de la discapacidad en Argentina-2008/2012", presentado ante el Comité sobre los derechos de las personas con discapacidad. 8 período de sesiones/evaluación sobre argentina (en línea). <http://www.redi.org.ar/Documentos/Informes/Informe-alternativo-al-comite-sobre-los-derechos-de-las-personas.pdf>, acceso 29 de agosto de 2019.

Rehabilitación Internacional y Red por los Derechos de las Personas con Discapacidad (2010): Capacidad jurídica y acceso a la justicia: una propuesta de reforma legal desde las organizaciones de personas con discapacidad (en línea). <https://es.calameo.com/read/0040346979bb7f8928e29>, acceso 29 de agosto de 2019.

Tamayo Sáez, M. (1997): “El análisis de las políticas públicas”. En Bañón, R. y Carrillo, E. (comps.). La Nueva Administración Pública. Madrid: Alianza Universidad Textos. 